\title{
Equilibrium, Kinetic, and Thermodynamic Studies on the Adsorption of Cadmium from Aqueous Solution by Modified Biomass Ash
}

\author{
Lei Xu, ${ }^{1,2,3,4}$ Xuebo Zheng, ${ }^{1,2,3,4}$ Hongbiao Cui, ${ }^{5}$ Zhenqiu Zhu, ${ }^{1,2,3,4}$ \\ Jiani Liang, ${ }^{1,2,3}$ and Jing Zhou ${ }^{1,2,3,4}$ \\ ${ }^{1}$ Institute of Soil Science, Chinese Academy of Sciences, Nanjing 210008, China \\ ${ }^{2}$ Key Laboratory of Soil Environment and Pollution Remediation, Chinese Academy of Science, Nanjing 210008, China \\ ${ }^{3}$ National Engineering and Technology Research Center for Red Soil Improvement, Red Soil Ecological Experiment Station, \\ Chinese Academy of Sciences, Liujiazhan Plantation, Yingtan 335211, China \\ ${ }^{4}$ University of Chinese Academy of Sciences, Beijing 100049, China \\ ${ }^{5}$ School of Earth and Environment, Anhui University of Science and Technology, Huainan 232001, China
}

Correspondence should be addressed to Jing Zhou; zhoujing@issas.ac.cn

Received 27 September 2016; Revised 19 December 2016; Accepted 22 January 2017; Published 28 February 2017

Academic Editor: Guillermo Mendoza-Diaz

Copyright (c) 2017 Lei Xu et al. This is an open access article distributed under the Creative Commons Attribution License, which permits unrestricted use, distribution, and reproduction in any medium, provided the original work is properly cited.

\begin{abstract}
Natural biomass ash of agricultural residuals was collected from a power plant and modified with hexagonal mesoporous silica and functionalized with 3-aminopropyltriethoxysilane. The physicochemical and morphological properties of the biomass ash were analyzed by ICP-OES, SEM, TEM-EDS, FTIR, and BET analysis. The adsorption behavior of the modified product for Cd ${ }^{2+}$ in aqueous solution was studied as a function of $\mathrm{pH}$, initial metal concentration, equilibrium time, and temperature. Results showed that the specific surface area of the modified product was 9 times that of the natural biomass ash. The modified biomass ash exhibited high affinity for $\mathrm{Cd}^{2+}$ and its adsorption capacity increased sharply with increasing $\mathrm{pH}$ from 4.0 to 6.0. The maximum adsorption capacity was $23.95 \mathrm{mg} / \mathrm{g}$ in a $\mathrm{pH} 5$ solution with an initial metal concentration of $50 \mathrm{mg} / \mathrm{L}$ and a contact time of $90 \mathrm{~min}$. The adsorption of $\mathrm{Cd}^{2+}$ onto the modified biomass ash was well fitted to the Langmuir model and it followed pseudo-second-order kinetics. Thermodynamic analysis results showed that the adsorption of $\mathrm{Cd}^{2+}$ was spontaneous and endothermic in nature. The results suggest that the modified biomass ash is promising for use as an inexpensive and effective adsorbent for $\mathrm{Cd}^{2+} \mathrm{removal}_{\text {from }}$ aqueous solution.
\end{abstract}

\section{Introduction}

Biomass ash is a by-product from the combustion of biomass feedstock at a combustion plant. During combustion, the inorganic constituents of biomass form biomass ash, increasing its accumulation in the environment $[1,2]$. Since biomass ash shows good adsorption capacity for heavy metals, it has been increasingly used as a low-cost and environmentfriendly adsorbent to remove the heavy metals such as $\mathrm{Cd}^{2+}, \mathrm{Pb}^{2+}$, and $\mathrm{Cu}^{2+}$ from wastewater $[3,4]$. Removal of heavy metals by adsorption is considered simpler to operate and less expensive, as compared with traditional techniques such as ion exchange, chemical precipitation, electrochemical treatment, membrane technology, evaporation, and solidification [5]. However, the adsorption capacity of natural biomass ash for particular heavy metals from aqueous solution is lower than some commercial or modified adsorbents [6]. Appropriate modification of biomass ash may enhance its adsorption capacity of heavy metals from wastewater [7].

Various mesoporous materials based on silicon dioxide have been extensively studied and partially commercialized. These materials are regarded as good adsorbents because of their large specific surface area, high thermal and mechanical 
stability, homogeneous pore morphology, high functionalization, and high adsorption capacity [8]. Furthermore, the adsorption capacity of mesoporous materials for heavy metal ions has been increased by combining particular organic functionalities on the surface and/or inside the pores of the material [9-11]. The modified materials with nanostructures have been shown to effectively remove heavy metals from industrial wastewater [12]. Some studies have been conducted to synthesize a new material by using coal fly ash and a functionalized mesoporous material. In fact, biomass ash has a high silicon content which gives it the potential to become a silica skeleton [13]. However, biomass ash has never been modified by this way.

Cadmium $(\mathrm{Cd})$ is a highly toxic and carcinogenic heavy metal discharged into water from mining, smelting, electroplating, and alloy manufacturing, among various industries [14]. Unlike many organic pollutants, Cd cannot be degraded and constantly accumulate in the environment, causing a serious threat to aquatic ecosystems and human health [1519]. It is therefore critical to remove $\mathrm{Cd}$ from industrial wastewater before discharge into the environment. Removal of $\mathrm{Cd}$ ions $\left(\mathrm{Cd}^{2+}\right)$ from aqueous solutions by absorption has been reported, for example, using peanut shell, zeolite, coal fly ash, activated carbon, and biochar [20-23]. To our knowledge, the removal of $\mathrm{Cd}^{2+}$ by adsorption onto biomass ash, particularly its modified product, has never been studied.

The aim of this study was to develop a low-cost and efficient mesoporous adsorbent with high stability in acidic medium by modification of biomass ash with mesoporous silica and organosilane. The physicochemical and morphological properties of the modified product were characterized. The adsorption characteristics of this modified biomass ash for $\mathrm{Cd}^{2+}$ in aqueous solution had been researched using batch experiments. The results will contribute to understanding about the kinetic and thermodynamic mechanisms of this new material for removal of $\mathrm{Cd}^{2+}$ from aqueous solution.

\section{Materials and Methods}

2.1. Biomass Ash. The biomass ash sample was collected from a power plant firing agricultural residues in Anhui province, China. A mixture of agricultural residues, such as wheat stem, maize straw, groundnut shell, and cotton stalk, was used as feedstock in the power plant. The residues were fired in a traveling-grate furnace at $\sim 850^{\circ} \mathrm{C}$ with excess air. The biomass ash was collected from the tank located below the grate.

2.2. Biomass Ash Modification. The biomass ash was modified with a hexagonal mesoporous silica (HMS) matrix by cocondensation [8]. First, $1.24 \mathrm{~g}$ of dodecylamine was dissolved in $10 \mathrm{~mL}$ of alcohol, followed by addition of a mixture of $1.24 \mathrm{~g}$ of biomass ash in $90 \mathrm{~mL}$ of ultrapure water (CN61 M-UPR-I-20L) under stirring at $1000 \mathrm{rpm}$. Next, $6.09 \mathrm{~mL}$ of tetraethyl orthosilicate and $0.71 \mathrm{~mL}$ of $10 \%(\mathrm{w} / \mathrm{v}) 3-$ aminopropyltriethoxysilane [APS, $\mathrm{NH}_{2}\left(\mathrm{CH}_{2}\right) 3 \mathrm{Si}\left(\mathrm{OC}_{2} \mathrm{H}_{5}\right)_{3}$ ], an organosilane, were added into the reaction mixture. After $30 \mathrm{~s}, 0.94 \mathrm{~mL}$ of trimethylbenzene was added and the mixture was then stirred for $24 \mathrm{~h}$. Finally, the mixture was filtered through a $0.45 \mu \mathrm{m}$ filter membrane and the residue was air dried at room temperature. The remaining trimethylbenzene was Soxhlet extracted with $125 \mathrm{~mL}$ of alcohol for $5 \mathrm{~h}$ and the sample was air dried at room temperature for $24 \mathrm{~h}$.

\subsection{Physicochemical and Morphological Characterizations.} The physicochemical and morphological properties of the natural and modified biomass ash samples were evaluated. The elemental composition was analyzed by inductively coupled plasma-optical emission (ICP-OES) spectrometry using a Perkin Elmer Optima 2000 DV system (Perkin Elmer, Waltham, MA, USA). The surface morphology was observed using an S-4800 scanning electron microscope (SEM; Hitachi, Tokyo, Japan) [24]. Topographic analysis and quantification of the components were performed using a JEM-2010HT transmission electron microscope (TEM; JEOL Ltd., Akishima, Tokyo, Japan) equipped with an energydispersive spectrometer (EDS). Functional groups were characterized by Fourier transform-infrared spectrometry (FTIR) using a Spectrum Two ${ }^{\mathrm{TM}}$ IR spectrometer (Perkin Elmer) in the range $4000-500 \mathrm{~cm}^{-1}$ [25]. The specific surface area of the materials was determined by BET method [24].

2.4. Adsorption Experiments. In order to evaluate the $\mathrm{Cd}^{2+}$ adsorption capacity of biomass ash and the modified material, batch adsorption experiments were carried out using guaranteed reagents. Cadmium solutions used in the experiment were prepared from a standard solution of $100 \mathrm{mg} / \mathrm{L}$ $\mathrm{Cd}\left(\mathrm{NO}_{3}\right)_{2}$ in $0.5 \mathrm{~mol} / \mathrm{L} \mathrm{HNO}_{3}$ and ultrapure water (CN61MUPR-I-20L). The $\mathrm{pH}$ was adjusted with $0.1 \mathrm{~mol} / \mathrm{L} \mathrm{HNO}_{3}$ and $\mathrm{NaOH}$.

To determine the effect of $\mathrm{pH}, 0.1 \mathrm{~g}$ of adsorbent was added to $25 \mathrm{~mL}$ of $50 \mathrm{mg} / \mathrm{L} \mathrm{Cd}^{2+}$ solution in the $\mathrm{pH}$ range of 2.0-8.0. Adsorption isotherms were obtained with several initial adsorbate concentrations from 50 to $100 \mathrm{mg} / \mathrm{L}$ in $25 \mathrm{~mL}$ of solution at $\mathrm{pH} 5.0$ with $0.1 \mathrm{~g}$ of adsorbent. The experiments were carried out in $50 \mathrm{~mL}$ centrifuge tubes at $30^{\circ} \mathrm{C}$ with shaking at $150 \mathrm{rpm}$ for $24 \mathrm{~h}$. For thermodynamic studies, the experiments were repeated at $45^{\circ} \mathrm{C}$ and $60^{\circ} \mathrm{C}$. The adsorption kinetics was studied by adding $0.2 \mathrm{~g}$ of adsorbent into $100 \mathrm{~mL}$ of $100 \mathrm{mg} / \mathrm{L} \mathrm{Cd}^{2+}$ solution at $\mathrm{pH}$ 5.0. The experiments were carried out on a $150 \mathrm{rpm}$ reciprocal shaker at $30^{\circ} \mathrm{C}$ for varying time intervals, $0.5,1,2,3,5,10,15,30,60,90,120180,240$, and $300 \mathrm{~min}$.

The samples ( $5 \mathrm{~mL}$ each) were centrifuged at 4,000 rpm for $10 \mathrm{~min}$. The supernatants were filtered with a $0.45 \mu \mathrm{m}$ membrane and the $\mathrm{Cd}^{2+}$ concentrations in the aqueous phase were determined by atomic absorption spectrophotometry (SpectrAA-220, Varian, Palo Alto, CA, USA).

2.5. Data Processing. Microsoft Excel 2010 (Microsoft Corp., Redmond, WA, USA) and SPSS 20.0 (IBM SPSS, Somers, NY, USA) were used to process the data. 
TABLE 1: Elemental composition of biomass ash analyzed by ICP-OES.

\begin{tabular}{lcccccccccccccccc}
\hline Element & $\mathrm{Si}$ & $\mathrm{Ca}$ & $\mathrm{K}$ & $\mathrm{Al}$ & $\mathrm{Fe}$ & $\mathrm{Mg}$ & $\mathrm{Na}$ & $\mathrm{P}$ & $\mathrm{S}$ & $\mathrm{Mn}$ & $\mathrm{Ni}$ & $\mathrm{Zn}$ & $\mathrm{Cu}$ & $\mathrm{Cr}$ & $\mathrm{Pb}$ & $\mathrm{Cd}$ \\
Proportion (\%) & 12.04 & 4.31 & 3.31 & 2.11 & 1.08 & 0.65 & 0.42 & 0.41 & 0.073 & 0.034 & 0.018 & 0.015 & 0.0035 & 0.0022 & 0.0005 & 0.0002 \\
\hline
\end{tabular}

TABLE 2: Comparison of the BET analysis of functionalized hexagonal mesoporous silica, biomass ash, and synthesized matrix.

\begin{tabular}{lccc}
\hline Analysis & HMS-NH2 [42] & Fly ash & $\begin{array}{c}\text { Fly ash + HMS } \\
+10 \% \text { APS }\end{array}$ \\
\hline $\begin{array}{l}\text { BET surface } \\
\text { area }\left(\mathrm{m}^{2} / \mathrm{g}\right)\end{array}$ & 17 & $21.38 \pm 0.17$ & $185.81 \pm 0.15$ \\
\hline
\end{tabular}

\section{Results and Discussion}

3.1. Physicochemical and Morphological Characteristics of Natural and Modified Biomass Ash. The elemental analysis results showed that the major elements present in the natural biomass ash were silicon, calcium, and potassium at concentrations of 120.40, 43.14, and $33.11 \mathrm{mg} / \mathrm{g}$, respectively (Table 1). The SEM analysis results revealed the presence of numerous sheet particles with diameters between 10 and $60 \mu \mathrm{m}$ in the natural biomass ash; these particles were dispersed well (Figure 1(a)). The appearance of the modified biomass ash was markedly different from the natural biomass ash with a clear spherical structure. The hexagonal structure changed after reaction with biomass ash. In the presence of silicate, the modified hexagonal structure acted as a catalyst, increasing the reactivity of tetraethyl orthosilicate. The specific surface area of the modified biomass ash improved, and the surface was more smooth and homogeneous (Figure 1(b)).

The TEM-EDS results of elemental composition showed the presence of $\mathrm{C}, \mathrm{O}, \mathrm{Si}, \mathrm{Al}, \mathrm{Fe}$, and $\mathrm{K}$ in the modified biomass ash (Figure 1(d)). FTIR analysis confirmed the presence of $\mathrm{N}$ in the modified biomass ash, indicating that the biomass ash had been functionalized by the primary amine (APS). The FTIR spectrum of the modified biomass ash (Figure 1(e)) demonstrates an intense absorption band at $3330 \mathrm{~cm}^{-1}$; this can be attributed to the $\mathrm{O}-\mathrm{H}$ bonds of the silanol groups. Other absorption bands appear at 850 and $1044 \mathrm{~cm}^{-1}$, which was related to the symmetric and asymmetric $\mathrm{Si}-\mathrm{O}-$ Si vibrations, respectively. After the functionalization with $10 \%$ APS and HMS matrix, the spectrum of the modified biomass ash was clearly different compared with that of the natural biomass ash; a broad signal appears between 3000 and $3600 \mathrm{~cm}^{-1}$ which can be attributed to the improved number of silanol groups [24]. The stretching bands can be attributed to the $\mathrm{N}-\mathrm{H}$ group of APS, and the band at $1488.2 \mathrm{~cm}^{-1}$ corresponds to the bending vibration of the $\mathrm{N}-\mathrm{H}$ groups.

The results of BET analysis showed that the specific surface area of modified biomass ash was 9 times that of the nature biomass ash, $21.38 \pm 0.17 \mathrm{~m}^{2} / \mathrm{g}$ versus $185.81 \pm$ $0.15 \mathrm{~m}^{2} / \mathrm{g}$ (Table 2). The improved specific surface area indicates that a functional mesoporous material was obtained.
3.2. Effect of $p H$ on Cadmium Adsorption Capacity. The $\mathrm{pH}$ is an important factor in removing heavy metals by adsorption from aqueous solutions $[26,27]$. Figure 2 shows the effects of different initial $\mathrm{pH}$ values on the load capacity $(\mathrm{mg} / \mathrm{g})$ for $\mathrm{Cd}^{2+}$ of the two materials. The $\mathrm{Cd}^{2+}$ adsorption was found to be highly $\mathrm{pH}$-dependent. At $\mathrm{pH}<4$, both the natural and modified biomass ash showed a significantly low adsorption capacity, for natural biomass ash, the adsorption capacity was only $1 \mathrm{mg} / \mathrm{g}$, and as to the modified biomass ash, it was about three times larger than the natural biomass ash. When the $\mathrm{pH}$ of the solution was increased, the adsorption capacity of the biomass ash and the modified biomass ash increased sharply, and when the $\mathrm{pH}$ reached 6 , the adsorption capacity of modified biomass ash reached $12 \mathrm{mg} / \mathrm{g}$ which was 4 times more than the $\mathrm{pH}$ 2. The effect of $\mathrm{pH}$ on the adsorption of metals can be attributed to the surface charge of the adsorbent and the distribution of metal species [28].

The surface of biomass ash has a negative charge, which is transient and depends on the $\mathrm{pH}$ of the solution [28]. When the $\mathrm{pH}$ in solution is substantially low, the number of $\mathrm{H}_{3} \mathrm{O}^{+}$exceeds that of metal ions by many times; thus, the adsorbent surface is almost completely covered by $\mathrm{H}_{3} \mathrm{O}^{+}$, leading to a lower adsorption capacity for metal ions [29]. When the $\mathrm{pH}$ is gradually increased, an increasing number of $\mathrm{H}_{3} \mathrm{O}^{+}$are removed from the adsorbent surface, allowing the metal ions to approach to the active adsorption sites; this increases the binding of metal ions to the modified adsorbent surface through the mechanism of ion exchange [29]. At $\mathrm{pH}$ $>4$, the $\mathrm{H}_{3} \mathrm{O}^{+}$concentration is markedly reduced, which is beneficial to the adsorption of metal ions on the surface of the adsorbent. This phenomenon can be attributed to the existence of oxides such as $\mathrm{SiO}_{2}, \mathrm{Fe}_{2} \mathrm{O}_{3}$, and $\mathrm{Al}_{2} \mathrm{O}_{3}$, whose surface charge depends mainly on the $\mathrm{pH}$ in the solution. The exchange mechanism of $\mathrm{H}^{+}$and metal ions in solution can be represented by the following equations:

$$
\begin{gathered}
\mathrm{XOH}+\mathrm{H}_{3} \mathrm{O}^{+} \longrightarrow \mathrm{XOH}_{2}^{+}+\mathrm{H}_{2} \mathrm{O} \\
\mathrm{XOH}+\mathrm{OH}^{-} \longrightarrow \mathrm{XO}^{-}+\mathrm{H}_{2} \mathrm{O} \\
2\left(\mathrm{XO}^{-}\right)+\mathrm{M}^{2+} \longrightarrow(\mathrm{XO})_{2} \mathrm{M}
\end{gathered}
$$

where $\mathrm{X}$ represents $\mathrm{Si}, \mathrm{Fe}$, and $\mathrm{Al} ; \mathrm{M}$ represents metal.

With further increase of $\mathrm{pH}$, the negative charge on the adsorbent surface is improved, thus increasing the electrostatic force between the adsorbent and adsorbate [30, 31]. The maximum adsorption efficiency of $\mathrm{Cd}^{2+}$ on the natural and modified biomass ash was observed between $\mathrm{pH} 5$ and $\mathrm{pH}$ 6. At $\mathrm{pH}>6$, the weak adsorption of $\mathrm{Cd}^{2+}$ can be attributed to the precipitation of $\mathrm{Cd}$ species such as carbonates or hydroxides (Figure 2), according to the distribution of metal species affected by $\mathrm{pH}[32]$. 


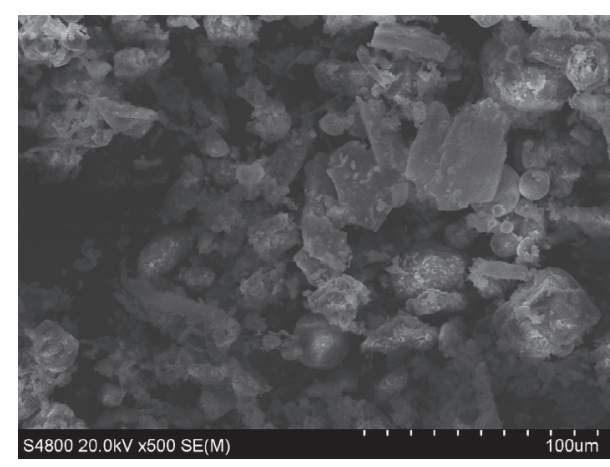

(a)

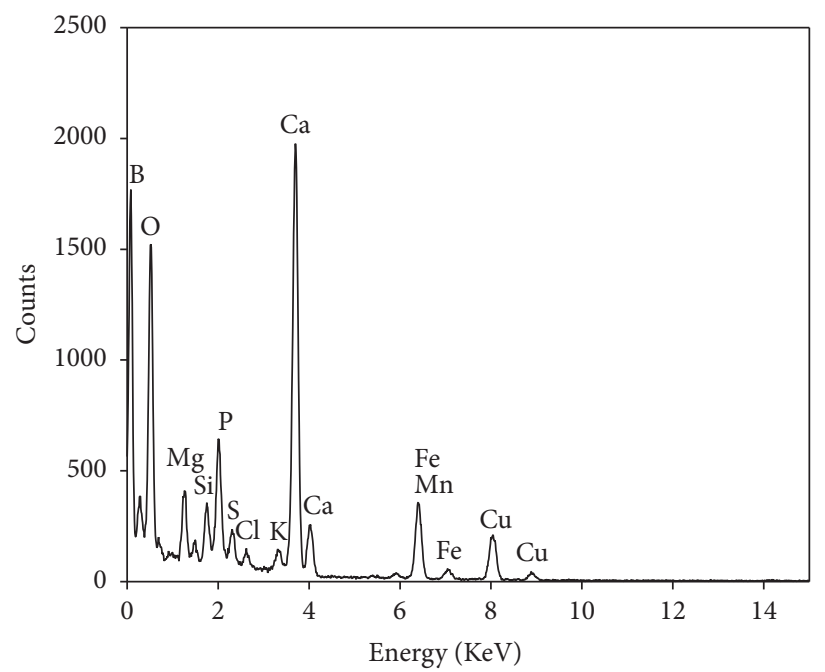

(c)

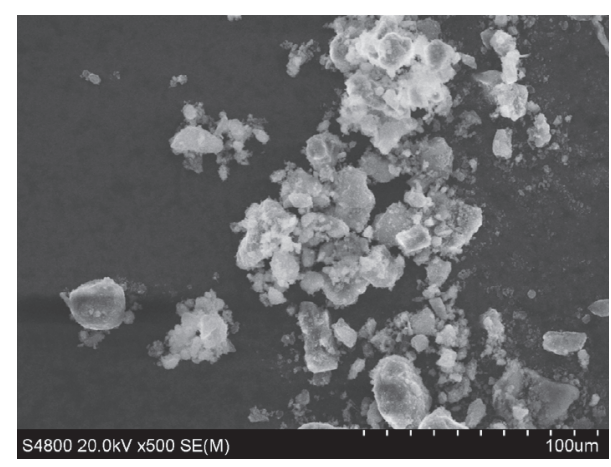

(b)

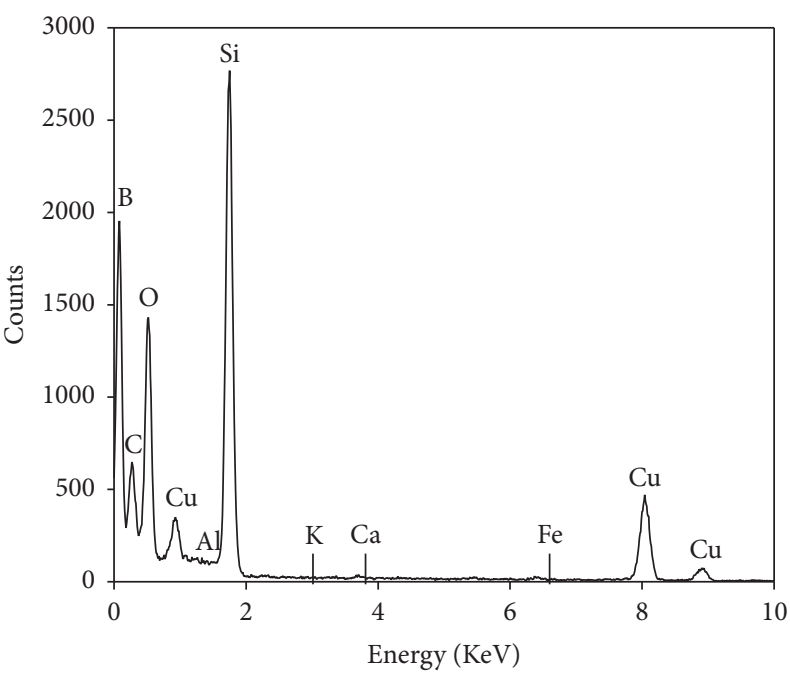

(d)

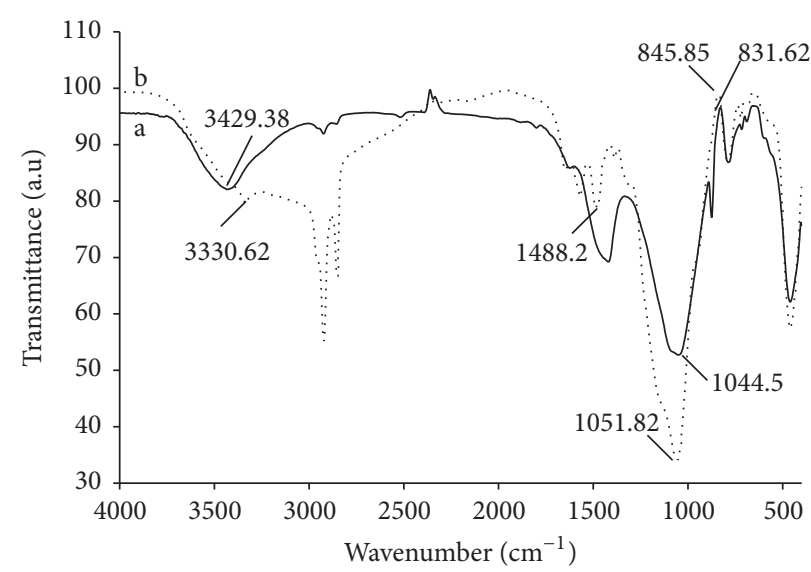

(e)

FIGURE 1: (a) SEM of biomass ash at $20 \mathrm{KeV}$; magnification 500. (b) SEM of synthesized matrix at $20 \mathrm{keV}$; magnification 500 . (c) EDS analysis of elemental composition of biomass ash. (d) EDS analysis of elemental composition of modified biomass ash and (e) FT-IR spectra: (a) biomass ash and (b) synthesized matrix.

The modified biomass ash was functionalized with $\mathrm{NH}_{2}$ groups, forming an amino-Cd complex with a higher stability constant favorable for the formation of this compound. The stability of the compound mainly depends on the $\mathrm{pH}$ which must be near 7 [8]. At $\mathrm{pH}<4$, the $\mathrm{H}^{+}$ions react with the lone pair of electrons of $\mathrm{N}$, preventing the binding of $\mathrm{Cd}^{2+}$ with
$\mathrm{NH}_{2}$ groups; at $\mathrm{pH}>6$, the $\mathrm{Cd}^{2+}$ ions precipitate due to the formation of insoluble species.

3.3. Adsorption Isotherms. Table 3 compares the $\mathrm{Cd}^{2+}$ adsorption capacity of the modified biomass ash with several types of adsorbents reported at the $\mathrm{pH}$ of 5-6. The modified 


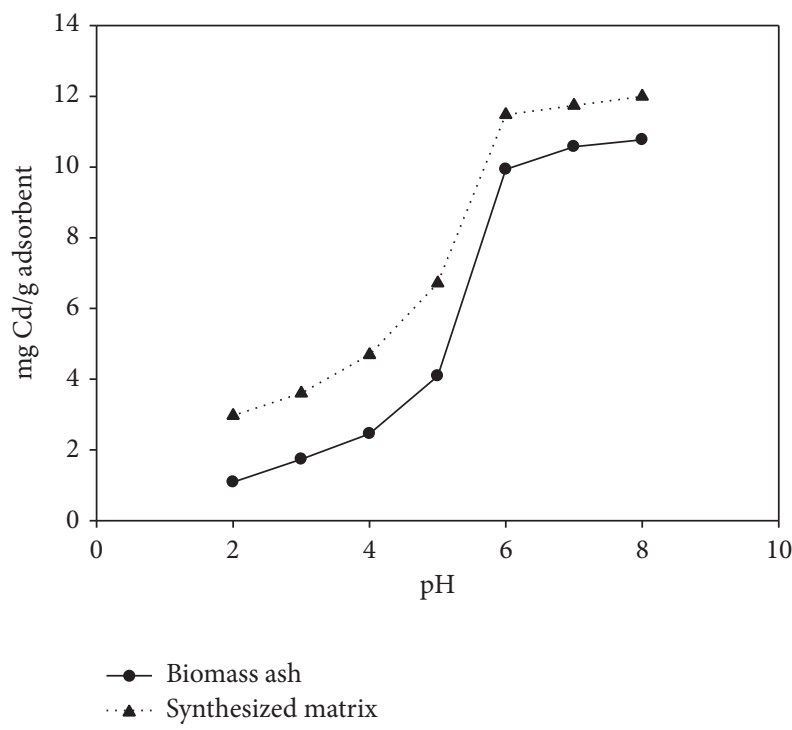

FIgURE 2: Effect of $\mathrm{pH}$ on the adsorption of $\mathrm{Cd}^{2+}$ on biomass ash and modified biomass ash (initial concentrations of $\mathrm{Cd}^{2+}, 50 \mathrm{mg} / \mathrm{L}$; biomass ash concentration, $4 \mathrm{~g} / \mathrm{L} ; \mathrm{T}=30^{\circ} \mathrm{C}$ ).

TABLE 3: Comparison of $\mathrm{Cd}^{2+}$ adsorption capacities of different absorbents.

\begin{tabular}{lccc}
\hline Absorbent & Adsorption capacity $(\mathrm{mg} / \mathrm{g})$ & $\mathrm{pH}$ & Reference \\
\hline Synthesized matrix & 25.00 & 5 & \\
Peanut shell & 0.93 & 5 & {$[22]$} \\
Banana peel & 5.71 & 5 & {$[43]$} \\
Biochar & 28.1 & 5 & {$[44]$} \\
Coal fly ash & 11.43 & 5 & {$[45]$} \\
Bentonite & 13.5 & 5.5 & {$[46]$} \\
Sepiolite & 8.11 & 5 & {$[47]$} \\
Zeolite & 6.72 & 6.5 & {$[48]$} \\
Activated carbon & 20.36 & 6 & {$[49]$} \\
\hline
\end{tabular}

biomass ash appears superior to most of the other materials, especially peanut shell, banana peel, sepiolite, zeolite, and natural biomass ash.

The Langmuir and Freundlich adsorption models were used to fit the adsorption data of the nature biomass ash and modified biomass ash to $\mathrm{Cd}^{2+}$ in aqueous solution.

The Langmuir isotherm is usually applied to monolayer adsorption on homogeneous surfaces with a finite number of adsorption sites. The linear form of Langmuir equation can be expressed as follows [33]:

$$
\frac{C_{e}}{q_{e}}=\frac{1}{q_{L} \cdot K_{L}}+\frac{C_{e}}{q_{L}},
$$

where $C_{e}$ represents the equilibrium concentration of the metal ions $(\mathrm{mg} / \mathrm{L}), q_{e}$ represents the amount of metal ions adsorbed by a unit mass adsorbent $(\mathrm{mg} / \mathrm{g}), q_{L}$ represents the maximum amount of the metal ions adsorbed by the unit mass adsorbent $(\mathrm{mg} / \mathrm{g})$, and $K_{L}$ represents the Langmuir constant (L/mg).

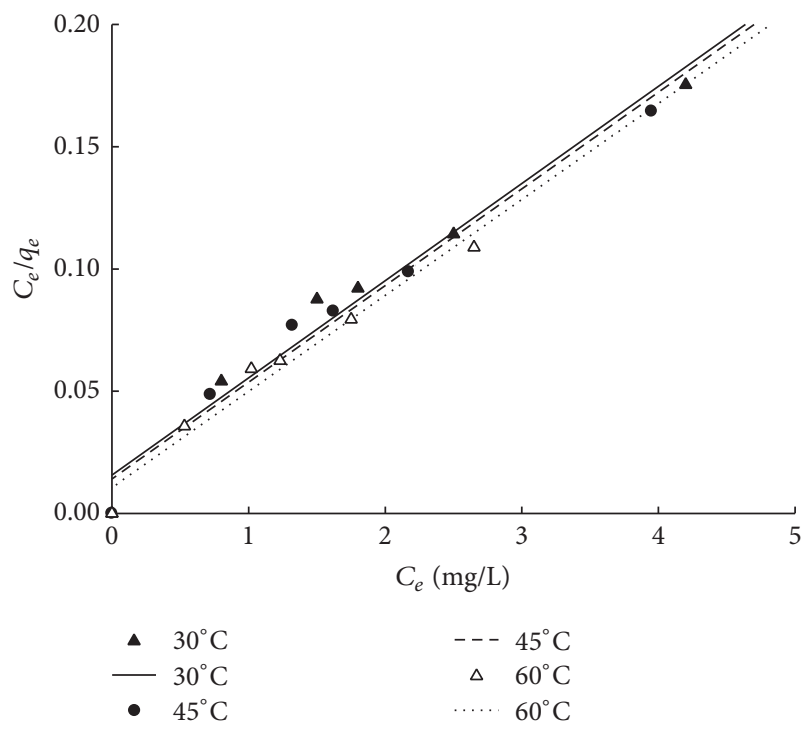

Figure 3: Langmuir model fit of modified biomass ash at different temperature.

The Freundlich isotherm assumes multilayer sorption on a heterogeneous surface. The linear form of Freundlich equation can be expressed as [34]

$$
\ln \left(q_{e}\right)=\ln \left(K_{F}\right)+\frac{1}{n} \ln \left(C_{e}\right),
$$

where $q_{e}$ and $C_{e}$ are the same as defined above and $K_{F}$ and $n$ are the Freundlich constants, which indicate the adsorption capacity and adsorption intensity of a given material, respectively. The $n$ values between 1 and 10 indicate favorable adsorption [35].

Table 4 shows the fitting results of the parameters of the isotherm models at different temperatures. Both the adsorption models well fitted with the experimental data obtained for the natural biomass ash and the modified matrix. The Langmuir model $\left(R^{2}=0.963\right)$ showed a slightly better fit than the Freundlich model $\left(R^{2}=0.960\right)$, probably because the adsorption of $\mathrm{Cd}^{2+}$ by the biomass ash belongs to monolayer adsorption (Figure 3 ). With regard to the favorability of adsorption, the $n$ values in the Freundlich model were greater than 3 at every temperature, indicating a favorable adsorption process of $\mathrm{Cd}^{2+}$ onto the modified biomass ash (Table 4). With the increase of temperature from $30^{\circ} \mathrm{C}$ to $60^{\circ} \mathrm{C}$, the adsorption capacity of the modified biomass ash slightly increased. The possible explanation is that the adsorption process is an endothermic reaction, and the temperature can increase the internal structure of the modified biomass ash [36], thereby enhancing its adsorption capacity.

3.4. Kinetic Studies. The adsorption rate of the adsorbent in solution for metal ions can be understood by studying the kinetics of the adsorption process. Through the fitting of the experimental data with appropriate kinetic models, the adsorption mechanism can be understood. Figure 4 shows 
TABLE 4: Values of the constants and fitting of the adjusted adsorption models.

\begin{tabular}{|c|c|c|c|c|c|c|c|}
\hline \multirow{2}{*}{ Adsorbent } & \multirow{2}{*}{ Temp $\left({ }^{\circ} \mathrm{C}\right)$} & \multicolumn{3}{|c|}{ Langmuir } & \multicolumn{3}{|c|}{ Freundlich } \\
\hline & & $q_{L}(\mathrm{mg} / \mathrm{g})$ & $K_{L}(\mathrm{~L} / \mathrm{mg})$ & $R^{2}$ & $n$ & $K_{F}(\mathrm{mg} / \mathrm{g})(\mathrm{mg} / \mathrm{L})^{1 / n}$ & $R^{2}$ \\
\hline \multirow{3}{*}{ Biomass ash } & 30 & 20.83 & 1.37 & 0.996 & 6.85 & 13.53 & 0.976 \\
\hline & 45 & 21.73 & 1.44 & 0.995 & 6.54 & 14.25 & 0.982 \\
\hline & 60 & 22.22 & 1.67 & 0.994 & 6.45 & 14.57 & 0.986 \\
\hline \multirow{3}{*}{ Modified biomass ash } & 30 & 25.00 & 2.50 & 0.970 & 3.03 & 15.94 & 0.960 \\
\hline & 45 & 25.64 & 3.55 & 0.974 & 3.34 & 16.48 & 0.953 \\
\hline & 60 & 25.67 & 6.94 & 0.976 & 3.12 & 18.01 & 0.967 \\
\hline
\end{tabular}

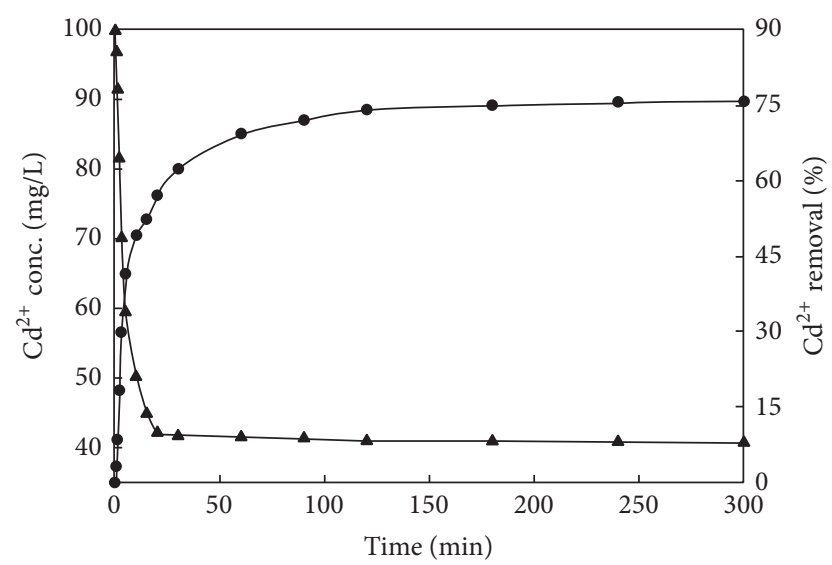

FIGURE 4: Sorption kinetics: concentration and removal (\%) of $\mathrm{Cd}^{2+}$ from aqueous solution versus sorption time (initial concentrations of $\mathrm{Cd}^{2+}, 100 \mathrm{mg} / \mathrm{L}$; biomass ash concentration, $2 \mathrm{~g} / \mathrm{L} ; \mathrm{T}=30^{\circ} \mathrm{C}$; initial $\mathrm{pH}$ 5.0).

the kinetics of $\mathrm{Cd}^{2+}$ sorption from aqueous solution onto the modified biomass ash (residual $\mathrm{Cd}^{2+}$ concentration versus contact time). The residual $\mathrm{Cd}^{2+}$ concentration was reduced sharply during the first 40-50 min and dropped to a value less than $40 \mathrm{mg} / \mathrm{L}$ within $120 \mathrm{~min}$. At the initial stage of the reaction, the $\mathrm{Cd}^{2+}$ can be rapidly absorbed onto the adsorbent surface with a high number of active adsorption sites. As the adsorption proceeded, an increasing number of active adsorption sites are occupied by $\mathrm{Cd}^{2+}$, leading to a reduction in the sorption rate. The slower diffusion of $\mathrm{Cd}^{2+}$ onto the interior matrix of the modified biomass ash may also lead to the slower adsorption at the late stage [37].

In order to analyze the adsorption rate of $\mathrm{Cd}^{2+}$ on the modified biomass ash, we filled the results of the dynamic analysis to the pseudo-first-order and pseudo-second-order rate equations [38]. The two equations can be expressed as follows:

$$
\begin{aligned}
\ln \left(Q_{e}-Q_{t}\right) & =\ln Q_{e}-k_{1} t \\
\frac{t}{Q_{t}} & =\frac{1}{k_{2} Q_{e}{ }^{2}}+\frac{t}{Q_{e}},
\end{aligned}
$$

where $Q_{e}$ is the adsorption capacity $(\mathrm{mg} / \mathrm{g}$ ) at equilibrium, $Q_{t}$ is the amount $(\mathrm{mg} / \mathrm{g})$ of material adsorbed at time $t, k_{1}$

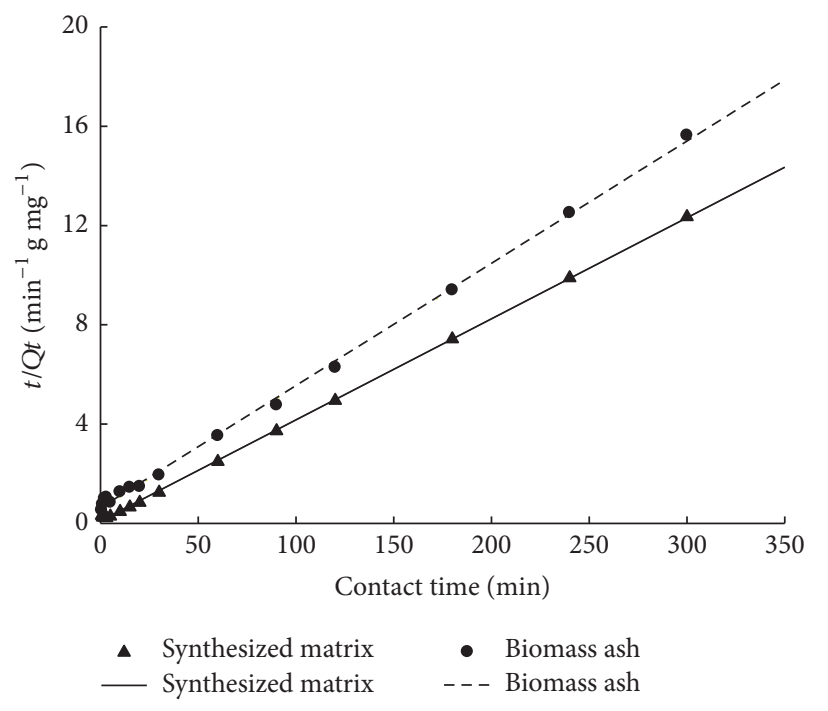

FIGURE 5: Plots of the pseudo-second-order kinetics for the adsorptions of $\mathrm{Cd}^{2+}$ on biomass ash and the synthesized matrix (initial concentrations of $\mathrm{Cd}^{2+}, 100 \mathrm{mg} / \mathrm{L}$; biomass ash concentration, $2 \mathrm{~g} / \mathrm{L}$; $T=30^{\circ} \mathrm{C} ; \mathrm{pH} 5.0$ ).

represents the rate constant $\left(\mathrm{min}^{-1}\right)$ of the pseudo-first-order model, and $k_{2}$ is the rate constant $\left(\mathrm{g} \cdot \mathrm{mg}^{-1} \cdot \mathrm{min}^{-1}\right)$ of the pseudo-second-order model.

Table 5 shows the kinetic parameters of the adsorption for $\mathrm{Cd}^{2+}$ on the biomass ash at $30^{\circ} \mathrm{C}$. For the pseudosecond-order model, the $R^{2}$ values were higher than those obtained using the pseudo-first-order model, especially for the modified biomass ash. The pseudo-second-order kinetic equations of the natural and modified biomass ash were higher than 0.99 (Figure 5), suggesting that the adsorption of $\mathrm{Cd}^{2+}$ followed the pseudo-second-order model and that $\mathrm{Cd}^{2+}$ ions were adsorbed onto the surface of both materials by chemical adsorption. The chemical adsorption may be caused by the reaction force and the coordination process between the $\mathrm{Cd}^{2+}$ and $\mathrm{N}-\mathrm{H}$ groups $\left(-\mathrm{NH}_{2}\right.$ and $\left.-\mathrm{NH}-\right)$ on the surface of the modified biomass ash.

3.5. Thermodynamic Studies. Thermodynamic parameters including the standard Gibbs free energy $\left(\Delta G^{0}\right)$, the standard 
TABLE 5: Kinetic parameters for biomass ash and the synthesized matrix.

\begin{tabular}{|c|c|c|c|c|c|}
\hline \multirow{2}{*}{ Adsorbent } & \multirow{2}{*}{$\operatorname{Temp}\left({ }^{\circ} \mathrm{C}\right)$} & \multicolumn{2}{|c|}{ Pseudo-first-order model } & \multicolumn{2}{|c|}{ Pseudo-second-order model } \\
\hline & & $k_{1}\left(\min ^{-1}\right)$ & $R^{2}$ & $k_{2}\left(\mathrm{~g} \cdot \mathrm{mg}^{-1} \cdot \mathrm{min}^{-1}\right)$ & $R^{2}$ \\
\hline Biomass ash & 30 & $8.8 \times 10^{-3}$ & 0.724 & $3.71 \times 10^{-3}$ & 0.999 \\
\hline Synthesized matrix & & $9 \times 10^{-3}$ & 0.433 & $1.60 \times 10^{-2}$ & 1 \\
\hline
\end{tabular}

TABLE 6: Thermodynamic parameters for the synthesized matrix.

\begin{tabular}{lccc}
\hline \multirow{2}{*}{ Temp $\left({ }^{\circ} \mathrm{C}\right)$} & \multicolumn{3}{c}{ Thermodynamic parameters } \\
& $\Delta G^{0}\left(\mathrm{~kJ} \cdot \mathrm{mol}^{-1}\right)$ & $\Delta H^{0}\left(\mathrm{~kJ} \cdot \mathrm{mol}^{-1}\right)$ & $\Delta S^{0}\left(\mathrm{~J} \cdot \mathrm{mol}^{-1} \cdot \mathrm{K}^{-1}\right)$ \\
\hline 30 & -2.31 & & \\
45 & -3.35 & 39.35 & 137.49 \\
60 & -5.63 & & \\
\hline
\end{tabular}

enthalpy $\left(\Delta H^{0}\right)$, and the standard entropy $\left(\Delta S^{0}\right)$ for adsorption of $\mathrm{Cd}^{2+}$ onto the modified biomass ash were calculated using the following equations [39]:

$$
\begin{aligned}
\Delta G^{0} & =-R T \ln K_{L}^{\prime} \\
\ln \frac{K_{L 2}}{K_{L 1}} & =-\left(\frac{\Delta H^{0}}{R}\right)\left(\frac{T_{1}-T_{2}}{T_{2} T_{1}}\right) \\
\Delta S^{0} & =\frac{\Delta H^{0}-\Delta G^{0}}{T},
\end{aligned}
$$

where $K_{L}^{\prime}, K_{L 1}$, and $K_{L 2}$ are the Langmuir constants at $T, T_{1}$, and $T_{2}$, respectively; $R$ is the gas constant $\left(8.314 \mathrm{~J} \cdot \mathrm{mol}^{-1} \cdot \mathrm{K}^{-1}\right)$.

$\Delta G^{0}$ is the adsorption driving force, which depends on $\Delta H^{0}$ and $\Delta S^{0}$. Table 6 shows the thermodynamic parameters of $\mathrm{Cd}^{2+}$ adsorption on the modified biomass ash at different temperatures. The negative values of $\Delta G$ were indicative of favorable and spontaneous adsorption process. With the increase of temperature, the $\Delta G$ value was gradually decreased which showed that the increase of temperature was favorable to the adsorption process. The positive values of $\Delta S$ reflected the affinity of the modified biomass ash for $\mathrm{Cd}^{2+}$, while the positive value of $\Delta H$ indicated the adsorption was endothermic.

Moreover, adsorption can be divided into chemical adsorption and physical adsorption, both of which can occur simultaneously in one adsorption process [40]. The adsorption heat for van Edward force, hydrogen bond, ligand exchange, dipole interaction, and chemical bond is 4-10, 2$40, \approx 40,2-29$, and $>60 \mathrm{~kJ} \cdot \mathrm{mol}^{-1}$, respectively [41]. In our study, the $\Delta H$ value was $39.35 \mathrm{~kJ} / \mathrm{mol}$, indicating the adsorption by hydrogen bond and ligand exchange. Therefore, the adsorption of $\mathrm{Cd}^{2+}$ onto the modified biomass ash involved both physical and chemical adsorption.

\section{Conclusions}

A low-cost and efficient adsorbent was modified from biomass ash for the removal of $\mathrm{Cd}^{2+}$ from aqueous solution. Compared with the natural biomass ash, the modified material showed a much larger specific surface area and a greater number of active adsorption sites after modification with HMS and functionalization with APS. The modified product showed a better adsorption capacity for $\mathrm{Cd}^{2+}$ that was mainly dependent on the initial metal concentration and $\mathrm{pH}$. The adsorption of $\mathrm{Cd}^{2+}$ on the modified biomass ash was well fitted to the Langmuir model. The adsorption processes were endothermic and followed the pseudosecond-order kinetics. Notably, the modified biomass ash showed a substantially higher adsorption capacity compared with the natural biomass ash as well as several types of adsorbent reported previously. This study provides a feasible method for utilizing biomass ash in the environment. Further investigation is needed to test the adsorption capacity of the modified biomass ash for other metal species from water.

\section{Competing Interests}

The authors declare that they have no financial and personal relationships with other people or organizations that can inappropriately influence our work, there is no professional or other personal interest of any nature or kind in any product, service, and/or company that could be construed as influencing the position presented in the manuscript. The authors declare that the grant, scholarship, and funding do not lead to any conflict of interests. Additionally, the authors declare that there is no conflict of interests regarding the publication of this manuscript.

\section{Acknowledgments}

The authors acknowledge the financial support for this project by the National Basic Research Program of China (Grant no. 2013CB934302), the Chinese Academy of Agricultural Sciences (Grant no. 2015BAD05B01), and the National Natural Science Foundation of China (41571461, 41601340). They thank Hongyu Liu for BET, SEM, and FTIR analyses.

\section{References}

[1] P. McKendry, "Energy production from biomass (part 1): overview of biomass," Bioresource Technology, vol. 83, no. 1, pp. 37-46, 2002.

[2] A. A. Khan, W. de Jong, P. J. Jansens, and H. Spliethoff, "Biomass combustion in fluidized bed boilers: potential problems and remedies," Fuel Processing Technology, vol. 90, no. 1, pp. 21-50, 2009.

[3] W. Lei, D. Zhuobao, and W. Zhongxuan, "Experimental study on the adsorption of mercury with modification treatment rice husk ashes and scanning electron microscope analysis," Guangdong Chemical Industry, vol. 38, pp. 33-35, 2011. 
[4] X. Li, Y. Xie, and Yangyang, "Study on adsorption capacity and kinetic characteristics of plant ash for $\mathrm{Cd}^{2+}$ in sewage water," Journal of Northeast Agricultural University, vol. 44, pp. 39-42, 2013.

[5] S. K. Rautaray, B. C. Ghosh, and B. N. Mittra, "Effect of fly ash, organic wastes and chemical fertilizers on yield, nutrient uptake, heavy metal content and residual fertility in a ricemustard cropping sequence under acid lateritic soils," Bioresource Technology, vol. 90, no. 3, pp. 275-283, 2003.

[6] B. Kiran, A. Kaushik, and C. P. Kaushik, "Response surface methodological approach for optimizing removal of Cr (VI) from aqueous solution using immobilized cyanobacterium," Chemical Engineering Journal, vol. 126, no. 2-3, pp. 147-153, 2007.

[7] F. A. B. Silva and F. L. Pissetti, "Adsorption of cadmium ions on thiol or sulfonic-functionalized poly(dimethylsiloxane) networks," Journal of Colloid and Interface Science, vol. 416, pp. 95100, 2014.

[8] A. Walcarius and L. Mercier, "Mesoporous organosilica adsorbents: nanoengineered materials for removal of organic and inorganic pollutants," Journal of Materials Chemistry, vol. 20, no. 22, pp. 4478-4511, 2010.

[9] J. Cao, Y. Wu, Y. Jin, P. Yilihan, and W. Huang, "Response surface methodology approach for optimization of the removal of chromium(VI) by NH2-MCM-41," Journal of the Taiwan Institute of Chemical Engineers, vol. 45, no. 3, pp. 860-868, 2014.

[10] J. Liu, X. Feng, G. E. Fryxell, L.-Q. Wang, A. Y. Kim, and M. Gong, "Hybrid mesoporous materials with functionalized monolayers," Advanced Materials, vol. 10, no. 2, pp. 161-165, 1998.

[11] L. Shao and J. Chen, "Synthesis and application of nanoparticles by a high gravity method," China Particuology, vol. 3, no. 1-2, pp. 134-135, 2005.

[12] S. E. Létant, T. W. Van Buuren, and L. J. Terminello, "Nanochannel arrays on silicon platforms by electrochemistry," Nano Letters, vol. 4, no. 9, pp. 1705-1707, 2004.

[13] G. Wang, L. Shen, and C. Sheng, "Characterization of biomass ashes from power plants firing agricultural residues," Energy and Fuels, vol. 26, no. 1, pp. 102-111, 2011.

[14] F. Fu and Q. Wang, "Removal of heavy metal ions from wastewaters: a review," Journal of Environmental Management, vol. 92, no. 3, pp. 407-418, 2011.

[15] B. He, Z. Yun, J. Shi, and G. Jiang, "Research progress of heavy metal pollution in China: sources, analytical methods, status, and toxicity," Chinese Science Bulletin, vol. 58, no. 2, pp. 134-140, 2013.

[16] S. Mishra, S. P. Dwivedi, and R. K. Singh, "A review on epigenetic effect of heavy metal carcinogens on human health," The Open Nutraceuticals Journal, vol. 3, no. 1, pp. 188-193, 2010.

[17] Z. Huang, X.-D. Pan, P.-G. Wu, J.-L. Han, and Q. Chen, "Heavy metals in vegetables and the health risk to population in Zhejiang, China," Food Control, vol. 36, no. 1, pp. 248-252, 2014.

[18] K. K. I. U. Arunakumara, B. C. Walpola, and M.-H. Yoon, "Current status of heavy metal contamination in Asia's rice lands," Reviews in Environmental Science and Biotechnology, vol. 12, no. 4, pp. 355-377, 2013.

[19] V. Sheoran, A. S. Sheoran, and P. Poonia, "Role of hyperaccumulators in phytoextraction of metals from contaminated mining sites: a review," Critical Reviews in Environmental Science and Technology, vol. 41, no. 2, pp. 168-214, 2010.

[20] R. Barbosa, N. Lapa, H. Lopes, A. Günther, D. Dias, and B. Mendes, "Biomass fly ashes as low-cost chemical agents for $\mathrm{Pb}$ removal from synthetic and industrial wastewaters," Journal of Colloid and Interface Science, vol. 424, pp. 27-36, 2014.

[21] Z. Wang, G. Liu, X. Monica, F. Li, and H. Zheng, "Adsorption of Cd (II) varies with biochars derived at different pyrolysis temperatures," Huan Jing Ke Xue, vol. 35, no. 12, pp. 4735-4744, 2014.

[22] Y. Liu, X. Sun, and B. Li, "Adsorption of $\mathrm{Hg} 2+$ and $\mathrm{Cd} 2+$ by ethylenediamine modified peanut shells," Carbohydrate Polymers, vol. 81, no. 2, pp. 335-339, 2010.

[23] F. Simantiraki and E. Gidarakos, "Comparative assessment of compost and zeolite utilisation for the simultaneous removal of BTEX, Cd and $\mathrm{Zn}$ from the aqueous phase: Batch and Continuous Flow Study," Journal of Environmental Management, vol. 159, pp. 218-226, 2015.

[24] J. Pizarro, X. Castillo, S. Jara et al., "Adsorption of Cu2+ on coal fly ash modified with functionalized mesoporous silica," Fuel, vol. 156, pp. 96-102, 2015.

[25] F. Noli, G. Buema, P. Misaelides, and M. Harja, "New materials synthesized from ash under moderate conditions for removal of toxic and radioactive metals," Journal of Radioanalytical and Nuclear Chemistry, vol. 303, no. 3, pp. 2303-2311, 2015.

[26] K. O. Adebowale, E. I. Unuabonah, and B. I. Olu-Owolabi, "Kinetic and thermodynamic aspects of the adsorption of $\mathrm{Pb}^{2+}$ and $\mathrm{Cd}^{2+}$ ions on tripolyphosphate-modified kaolinite clay," Chemical Engineering Journal, vol. 136, no. 2-3, pp. 99-107, 2008.

[27] M.-Q. Jiang, X.-Y. Jin, X.-Q. Lu, and Z.-L. Chen, "Adsorption of $\mathrm{Pb}(\mathrm{II}), \mathrm{Cd}(\mathrm{II}), \mathrm{Ni}(\mathrm{II})$ and $\mathrm{Cu}(\mathrm{II})$ onto natural kaolinite clay," Desalination, vol. 252, no. 1-3, pp. 33-39, 2010.

[28] I. Cretescu, G. Soreanu, and M. Harja, "A low-cost sorbent for removal of copper ions from wastewaters based on sawdust/fly ash mixture," International Journal of Environmental Science and Technology, vol. 12, no. 6, pp. 1799-1810, 2015.

[29] S. Sen Gupta and K. G. Bhattacharyya, "Immobilization of $\mathrm{Pb}$ (II), Cd(II) and $\mathrm{Ni}$ (II) ions on kaolinite and montmorillonite surfaces from aqueous medium," Journal of Environmental Management, vol. 87, no. 1, pp. 46-58, 2008.

[30] S. Cetin and E. Pehlivan, "The use of fly ash as a low cost, environmentally friendly alternative to activated carbon for the removal of heavy metals from aqueous solutions," Colloids and Surfaces A: Physicochemical and Engineering Aspects, vol. 298, no. 1-2, pp. 83-87, 2007.

[31] F. Dawodu, G. Akpomie, and I. Ogbu, "Application of kinetic rate equations on the removal of copper (II) ions by adsorption unto Aloji Kaolinite clay mineral," International Journal of Multidisciplinary Sciences and Engineering, vol. 3, pp. 21-26, 2012.

[32] W. Stumm and J. Morgan, Aquatic Chemistry: Chemical Equilibria and Rates in Natural Waters, Wiley-Interscience, 1996.

[33] I. Langmuir, "The adsorption of gases on plane surfaces of glass, mica and platinum," Journal of the American Chemical Society, vol. 40, no. 9, pp. 1361-1403, 1918.

[34] H. Freundlich, "Over the adsorption in solution," The Journal of Physical Chemistry, vol. 57, p. e470, 1906.

[35] A. Bourliva, K. Michailidis, C. Sikalidis, A. Filippidis, and M. Betsiou, "Lead removal from aqueous solutions by natural Greek bentonites," Clay Minerals, vol. 48, no. 5, pp. 771-787, 2013.

[36] Y. S. Al-Degs, M. I. El-Barghouthi, A. H. El-Sheikh, and G. M. Walker, "Effect of solution $\mathrm{pH}$, ionic strength, and temperature on adsorption behavior of reactive dyes on activated carbon," Dyes and Pigments, vol. 77, no. 1, pp. 16-23, 2008. 
[37] T. Motsi, N. A. Rowson, and M. J. H. Simmons, "Adsorption of heavy metals from acid mine drainage by natural zeolite," International Journal of Mineral Processing, vol. 92, no. 1-2, pp. 42-48, 2009.

[38] S. Wang and H. Li, "Dye adsorption on unburned carbon: kinetics and equilibrium," Journal of Hazardous Materials, vol. 126, no. 1-3, pp. 71-77, 2005.

[39] V. K. Gupta and I. Ali, "Removal of lead and chromium from wastewater using bagasse fly ash-a sugar industry waste," Journal of Colloid and Interface Science, vol. 271, no. 2, pp. 321328, 2004.

[40] S. Y. Zhang Aiju and L. Zicheng, "Progress in research on synthesis mechanism of mesoporous materials and their applications," Journal of Hebei Institute of Technology, vol. 28, pp. 7579, 2006.

[41] J. Fu, Y. Li, C. Ye, and C. Lin, "Study on the adsoption kinetics and thermodynamics of DMF on macroporous adsorbents," Acta Scientiae Circumstantiae, vol. 32, no. 3, pp. 639-644, 2012.

[42] M. Machida, B. Fotoohi, Y. Amamo, T. Ohba, H. Kanoh, and L. Mercier, "Cadmium(II) adsorption using functional mesoporous silica and activated carbon," Journal of Hazardous Materials, vol. 221-222, pp. 220-227, 2012.

[43] J. Anwar, U. Shafique, Waheed-uz-Zaman, M. Salman, A. Dar, and $\mathrm{S}$. Anwar, "Removal of $\mathrm{Pb}(\mathrm{II})$ and $\mathrm{Cd}(\mathrm{II})$ from water by adsorption on peels of banana," Bioresource Technology, vol. 101, no. 6, pp. 1752-1755, 2010.

[44] H. Wang, B. Gao, S. Wang, J. Fang, Y. Xue, and K. Yang, "Removal of $\mathrm{Pb}(\mathrm{II}), \mathrm{Cu}(\mathrm{II})$, and $\mathrm{Cd}(\mathrm{II})$ from aqueous solutions by biochar derived from $\mathrm{KMnO} 4$ treated hickory wood," Bioresource Technology, vol. 197, pp. 356-362, 2015.

[45] H. Javadian, F. Ghorbani, H.-A. Tayebi, and S. M. H. Asl, "Study of the adsorption of Cd (II) from aqueous solution using zeolite-based geopolymer, synthesized from coal fly ash; kinetic, isotherm and thermodynamic studies," Arabian Journal of Chemistry, vol. 8, no. 6, pp. 837-849, 2015.

[46] B. Sadeghalvad, M. Armaghan, and A. Azadmehr, "Using Iranian Bentonite (Birjand Area) to remove cadmium from aqueous solutions," Mine Water and the Environment, vol. 33, no. 1, pp. 79-88, 2014.

[47] S. Hojati and H. Khademi, "Cadmium sorption from aqueous solutions onto Iranian sepiolite: kinetics and isotherms," Journal of Central South University, vol. 20, no. 12, pp. 3627-3632, 2013.

[48] T. C. Nguyen, P. Loganathan, T. V. Nguyen, S. Vigneswaran, J. Kandasamy, and R. Naidu, "Simultaneous adsorption of Cd, Cr, $\mathrm{Cu}, \mathrm{Pb}$, and $\mathrm{Zn}$ by an iron-coated Australian zeolite in batch and fixed-bed column studies," Chemical Engineering Journal, vol. 270, pp. 393-404, 2015.

[49] S. Ying, W. Caibin, H. Xuefeng, L. Luyan, and L. Jie, “Treatment $\mathrm{Cu}$-containing wastewater by using activated carbon made from coal ash," Environmental Chemistry, vol. 32, pp. 819-826, 2013. 

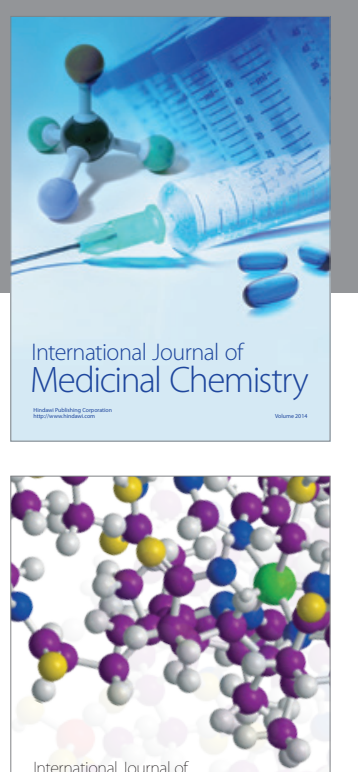

Carbohydrate Chemistry

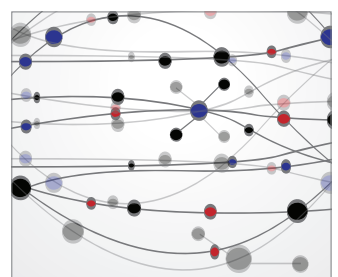

The Scientific World Journal
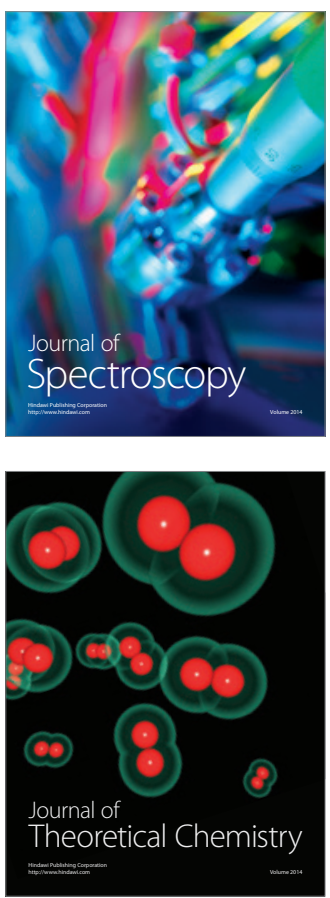
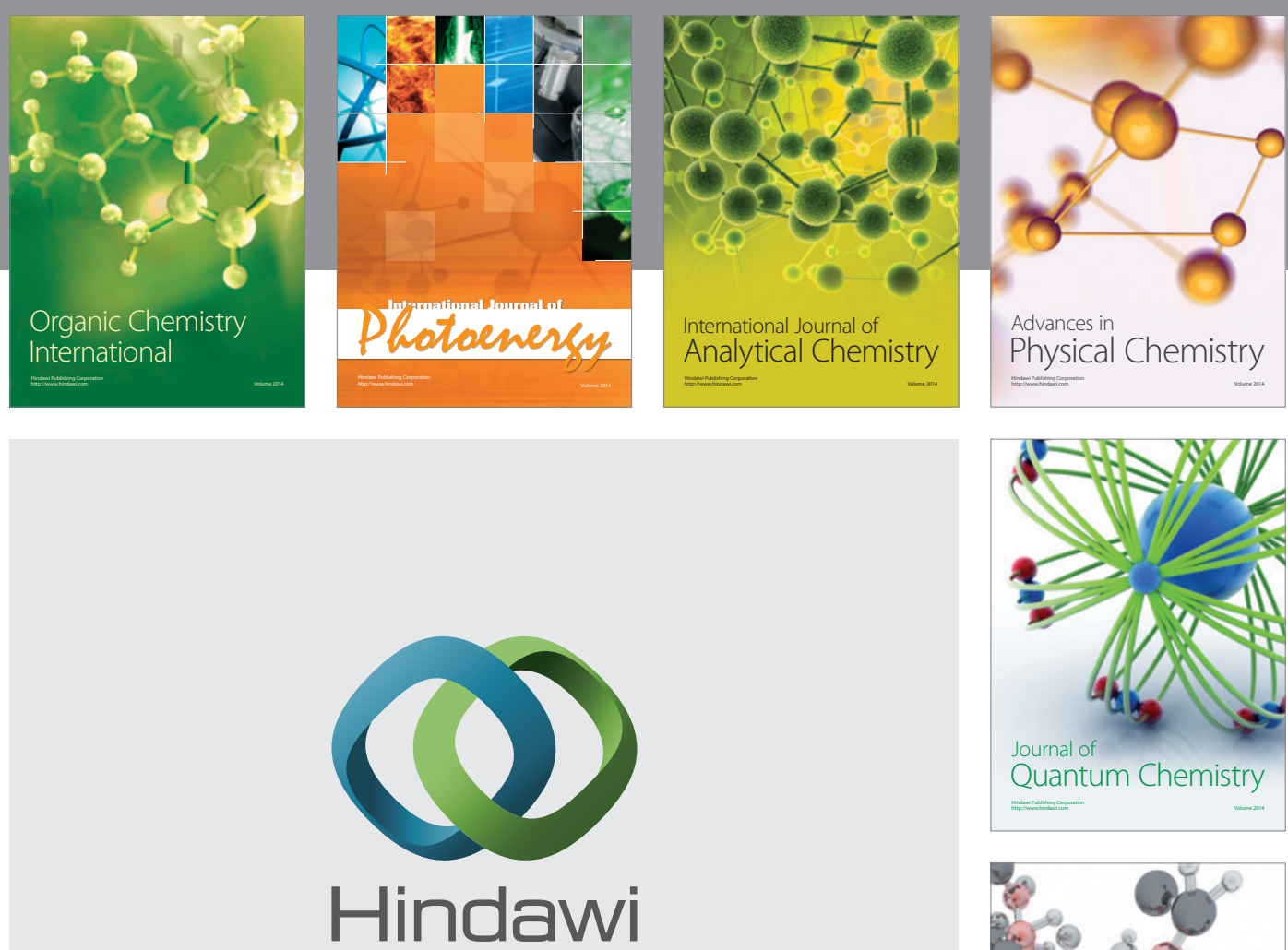

Submit your manuscripts at

https://www.hindawi.com

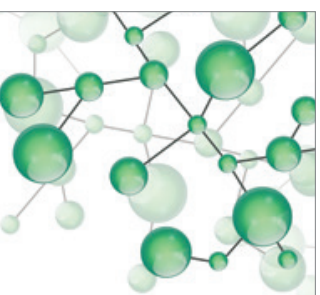

International Journal of

Inorganic Chemistry
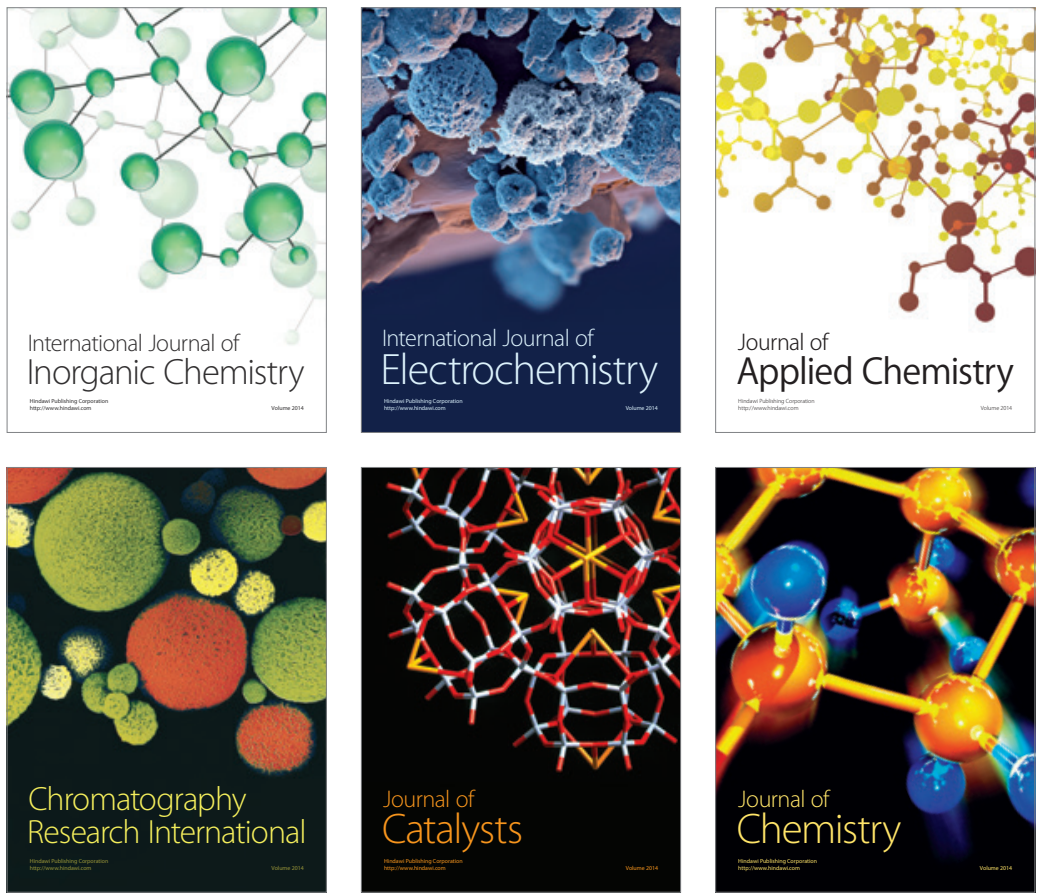

Journal of

Applied Chemistry
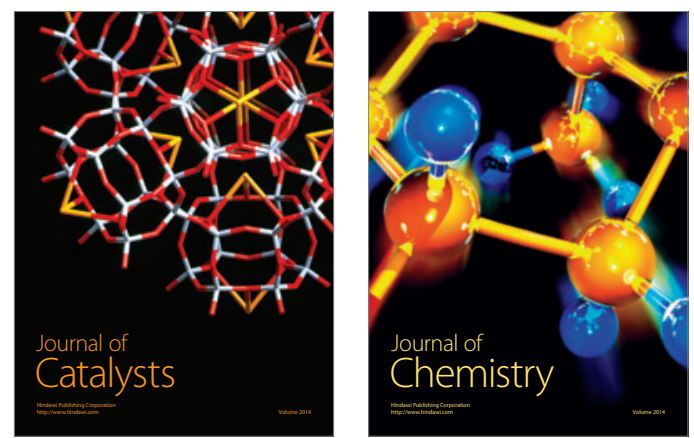
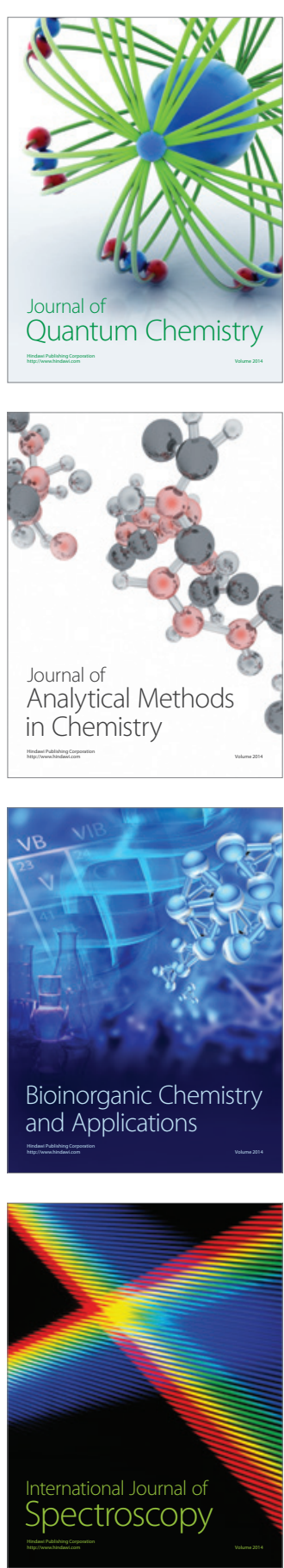